\title{
Understanding the Effects of Low Salinity on Fertilization Success and Early Development in the Sand Dollar Echinarachnius parma
}

Jonathan D. Allen

College of William and Mary, jdallen@wm.edu

Jan A. Pechenik

Follow this and additional works at: https://scholarworks.wm.edu/aspubs

Part of the Marine Biology Commons

\section{Recommended Citation}

Allen, Jonathan D. and Pechenik, Jan A., Understanding the Effects of Low Salinity on Fertilization Success and Early Development in the Sand Dollar Echinarachnius parma (2010). BIOLOGICAL BULLETIN, 218(2), 189-199.

10.1086/BBLv218n2p189

This Article is brought to you for free and open access by the Arts and Sciences at W\&M ScholarWorks. It has been accepted for inclusion in Arts \& Sciences Articles by an authorized administrator of W\&M ScholarWorks. For more information, please contact scholarworks@wm.edu. 


\title{
Understanding the Effects of Low Salinity on Fertilization Success and Early Development in the Sand Dollar Echinarachnius parma
}

\author{
JONATHAN D. ALLEN ${ }^{1} *$ AND JAN A. PECHENIK ${ }^{2}$ \\ ${ }^{1}$ Department of Biology, Bowdoin College, Brunswick, Maine 04011; and ${ }^{2}$ Department of Biology, \\ Tufts University, Medford, Massachusetts 02155
}

\begin{abstract}
Free-spawning marine invertebrates that live near shore or in estuaries may experience reduced fertilization success during low-salinity events. Although several studies have documented reproductive failure at reduced salinity in estuarine animals, few have looked at whether developmental failure is due to a failure of fertilization or to a failure of fertilized eggs to cleave. In this study, we examined the effects of salinities ranging from 18 to $32 \mathrm{psu}$ on fertilization success and early development in the sand dollar Echinarachnius parma. In addition to decoupling the effects of low salinity on fertilization from its effects on early cleavage, we also assessed whether eggs or sperm were the weak link in accounting for reproductive failure. We found that both fertilization and cleavage failed at salinities below about 22 psu but that development could be partially rescued by returning zygotes to full-strength seawater. We also found that sperm remained active and capable of fertilizing eggs even after being exposed to low salinities for $30 \mathrm{~min}$.. Taken together, these results suggest that reproductive failure at low salinities in E. parma is due more to an inability of the fertilized eggs to cleave than to an inability of sperm to fertilize eggs.
\end{abstract}

\section{Introduction}

Shallow-water or estuarine species exhibiting external fertilization may be especially susceptible to low-salinity stress. Fertilization and early development of the polychaete Nereis virens, for example, is rarely successful at salinities below about 22 psu (Ushakova and Sarantchova, 2004).

Received 20 August 2009; accepted 4 February 2010.

* To whom correspondence should be addressed, at Department of Biology, College of William and Mary, Williamsburg, VA 23185. E-mail: jdallen@wm.edu
Although some attention has been paid to the role of salinity variation in determining reproductive success, surprisingly little attention has been paid to how those effects are mediated, despite considerable interest in many other aspects of fertilization ecology over the past 25 years (e.g., Pennington, 1985; Levitan and Young, 1995; Podolsky and Strathmann, 1996; Yund, 2000; Podolsky, 2002; Johnson and Yund, 2008). There is a substantial literature on the effects of salinity on gamete longevity and fertilization success for marine algae (e.g., Brawley, 1992; Serrao et al., 1996; Steen, 2004), but surprisingly little comparable information for marine animals (but for examples of renewed interest in this topic, see Bekova et al., 2004; Kashenko, 2007; and Pechenik et al., 2007).

While several studies have considered the effects of low salinity on larval development and metamorphosis (e.g., Anger et al., 1998; Metaxas, 1998; Qiu et al., 2002), few have looked at the effects of low salinity on fertilization and cleavage. In one recent study, Pechenik et al. (2007) showed that in the free-spawning polychaete Hydroides elegans, poor development below salinities of about 20 psu was due more to an inability of eggs to cleave than to an inability of sperm to successfully fertilize the eggs. However, because polychaete eggs do not form a conspicuous envelope upon fertilization, there was no direct way to assess fertilization success; fertilization success had to be inferred from cleavage. Echinoderms seemed a promising alternative for such studies because their eggs typically form fertilization envelopes within $30 \mathrm{~s}$ of fertilization (Pearse and Cameron, 1991), allowing the effects of low salinity on fertilization to be distinguished from those on cleavage.

One of the few researchers to specifically investigate the effect of low salinity on both fertilization and cleavage was the remarkable E. E. Just (Byrnes and Eckberg, 2006). 
Working with the echinoid Echinarachnius parma, Just (1923, p. 19) concluded that "the failure to cleave is due to the action of dilute sea-water in interfering with the cleavage mechanism" - not with fertilization, since "eggs inseminated in dilutions of sea-water may separate membranes [i.e., form a fertilization envelope] though they do not cleave." However, Just never specified the salinities he worked with. Instead his data were presented as a function of "percent dilution of sea-water," with no report of the salinity of undiluted seawater or the actual data on percent cleavage. Moreover, he used tap water to make his dilutions, so some of the effects observed could have been at least partly caused by contaminants.

In this study we set out to repeat and extend key elements of Just's work on E. parma. In particular, we define the salinities at which fertilization envelopes form and at which cleavage occurs, and by transferring well-rinsed eggs to different salinities after their mixture with sperm, we more clearly differentiate the effects of low salinity on fertilization and cleavage. We also document the effect of reduced salinity on the timing of fertilization and cleavage, and examine for the first time the tolerance of sperm of this species to low salinities, assessing the relative sensitivity of the two types of gametes to low-salinity stress.

\section{Materials and Methods}

\section{General}

Adult specimens of the sand dollar Echinarachnius parma (Lamarck, 1816) were collected from the low intertidal zone at Cedar Beach, Harpswell, Maine $\left(43^{\circ} 44^{\prime} 37^{\prime \prime} \mathrm{N}\right.$; $\left.69^{\circ} 59^{\prime} 11^{\prime \prime} \mathrm{W}\right)$ and transported to the Bowdoin College marine laboratory (Orr's Island, ME), where they were housed in flow-through seawater aquaria at ambient temperature. The natural spawning season for E. parma along the southern Maine coast is June, July, and August, and all experiments were carried out during these months. All experiments were conducted at room temperature, about $22{ }^{\circ} \mathrm{C}$, and for each experiment gametes were obtained from 3-4 males and 2-3 females by intracoelomic injection of about $1 \mathrm{ml}$ of $0.5 \mathrm{~mol} \mathrm{l}^{-1} \mathrm{KCl}$. Eggs from each female were combined and well mixed prior to being subsampled for use in each experiment. All seawater was filtered to $0.45 \mu \mathrm{m}$ and oxygenated by vigorous agitation before use. All dilutions were made by adding reverse-osmosis filtered water. Except where otherwise indicated, all fertilizations were carried out using sperm concentrations of approximately $1 \times 10^{6}$ sperm $\mathrm{ml}^{-1}$, a choice based on results presented below for fertilization success at different sperm concentrations; and all experiments were conducted using 40-ml seawater suspensions in glass bowls, with three replicates per treatment unless otherwise noted. Eggs were examined for fertilization envelopes and cleavage, using compound microscopes at a magnification of $40 \times$. The elevation of a fertilization envelope was taken to indicate fertilization success, following standard protocol (e.g., Greenwood and Bennett, 1981; Ringwood, 1992; Levitan, 2002). We did not measure the $\mathrm{pH}$ of the seawater used in this study; however, the seawater at Bowdoin's marine laboratory typically ranges from 7.8 to 8.3, and a previous study (Pechenik et al., 2007) found that seawater $\mathrm{pH}$ was not affected by dilution with distilled water over a range of 10 to $35 \mathrm{psu}$.

Salinity was directly measured at the collection site on two occasions in the summer of 2009 by using a YSI 30 handheld conductivity meter. Salinity measurements of nearby surface waters were also collected from the GOMOOS (Gulf of Maine Ocean Observing System) buoy in lower Harpswell sound, about $2 \mathrm{~km}$ to the northwest of our collection site $\left(43^{\circ} 45^{\prime} 46^{\prime \prime} \mathrm{N} ; 69^{\circ} 59^{\prime} 16^{\prime \prime} \mathrm{W}\right)$.

\section{Fertilization success at different sperm concentrations}

Nearly dry sperm were obtained from three males and mixed together. A 200- $\mu$ l sample of the combined sperm suspension was diluted in $100 \mathrm{ml}$ of filtered seawater. A 1-ml subsample of this suspension (100\%) was withdrawn, and one drop of Lugol's iodine was added to stain the sperm. Sperm concentration was then determined with a hemacytometer at a magnification of $100 \times$. The concentration of the $100 \%$ suspension was $1.4 \times 10^{6}$ sperm ml$^{-1}$. Additional concentrations of 50\%, 25\%, $12.5 \%, 6.25 \%$, and $3.12 \%$ were then made by serial dilution of the $100 \%$ suspension, and $40 \mathrm{ml}$ of each suspension was poured into each of three replicate glass bowls.

Eggs were obtained from two females and held at approximately $800 \mathrm{eggs} \mathrm{ml}^{-1}$ before use. A 0.5 - $\mathrm{ml}$ subsample of the egg suspension was added to each bowl of sperm suspension. The samples were examined for fertilization envelopes after about 3-10 min, and examined for cleavage after about $2-2.5 \mathrm{~h}$.

\section{Fertilization and development at constant salinities}

This experiment was conducted to determine the range of salinities over which eggs could be fertilized and could cleave. In a pilot study, the following salinities were tested: $32,30,25,20,15$, and $10 \mathrm{psu}$. Based on the results of that study, the following salinities were tested in a subsequent experiment: $32,26,24,22,20$, and 18 psu. A $0.5-\mathrm{ml}$ subsample of egg suspension was first added to each dish (40 $\mathrm{ml}$ of seawater in each dish), the appropriate (small) volume of sperm suspension was added within $1 \mathrm{~min}$, and the suspension was then mixed gently by swirling each dish. The presence of fertilization envelopes was assessed about 30 min later, and the extent of cleavage was determined about $2 \mathrm{~h}$ after that. 


\section{Time course of cleavage at constant salinities}

Eggs from the above experiment at 32 psu were subsampled at about 30-min intervals to record changes in the frequency of 1-cell, 2-cell, and 4-cell stages. A separate experiment was later conducted to determine the effects of salinity on the timing of fertilization and early cleavage; in that experiment, eggs were examined for fertilization envelopes and cleavage at intervals for up to $10 \mathrm{~h}$. The following salinities were tested: $32,26,24,22,20,18$, and 16 psu.

\section{Effects of low salinity on cleavage}

Eggs were fertilized at full salinity (32 psu) and allowed to sit for about $20 \mathrm{~min}$ to allow fertilization envelopes to harden. The eggs were then carefully retained on a $50-\mu \mathrm{m}$ mesh filter that was then gently agitated in three successive beakers of full-strength filtered seawater to remove excess sperm. The rinsed eggs were transferred to dishes of lowsalinity seawater and subsampled after about 30-60 min to assess fertilization and cleavage. A suspension of unfertilized eggs was added to three samples of the final rinse water, and these eggs were checked for the presence of fertilization envelopes about $30 \mathrm{~min}$ later to test for the effectiveness of sperm removal. Additional eggs (with sperm added) remained at the initial full-strength salinity for the entire procedure (three replicates) to serve as a control, and eggs to which no sperm were added (three replicates) served as an additional control, to be certain that no eggs were inadvertently fertilized during collection.

\section{Rescue of eggs fertilized at low salinity}

The goal of this part of the study was to determine whether eggs mixed with sperm at low salinity could be "rescued" by transferring them to high-salinity seawater well before the time that first cleavage would normally occur. Conducting this experiment required that we be able to remove all non-adhering sperm before the transfer, so that there would be no free sperm available to fertilize eggs in full-strength seawater after the transfer. Gametes were mixed at each of the salinities tested previously (18-32 psu) in about 1 liter of solution. After 5 min, during which all eggs settled to the bottom of the container, most of the water was drained from each beaker by reverse filtration: a siphon tube was placed inside a mesh-bottomed beaker so that only water passing through the mesh was removed from the container, leaving the eggs behind. An additional liter of seawater at the same test salinity was then added to each beaker and the filtration repeated. Another liter of water at the test salinity was added and filtered; then, finally, a liter of full-strength seawater was added to each beaker and was also mostly drained off. Unfertilized eggs were then added to three subsamples of that rinse water to assess the effectiveness of sperm removal. The experimental eggs were examined after about $30 \mathrm{~min}$ to assess fertilization and again 2-3 h later to assess cleavage success. Additional samples (three replicates) remained the entire time at the original test salinities (including full-strength seawater) with sperm, as controls. Additional samples (three replicates) of eggs were never deliberately exposed to sperm and were subsequently monitored for fertilization and cleavage, to control for the possibility that eggs might have been inadvertently exposed to sperm during collection.

\section{Assessing the salinity tolerance of sperm}

Two sperm-tolerance experiments were conducted. In the first, $5 \mu \mathrm{l}$ of sperm suspension was added to dishes of seawater at either 18 or 20 psu (three replicates at each salinity). Egg suspension (300 $\mu \mathrm{l})$ was then added to each dish after $0,5,10,15$, or $30 \mathrm{~min}$. The eggs were examined about 10 min later to look for bound sperm and sperm swimming activity. In the second experiment, $5 \mu \mathrm{l}$ of concentrated sperm suspension was added to $1 \mathrm{ml}$ of seawater at 18 or $20 \mathrm{psu}$; sperm remained in that low-salinity solution for $0,5,10,15$, or $30 \mathrm{~min}$. Forty $\mathrm{ml}$ of full-strength (32 psu) seawater was then added to each bowl, and $0.5 \mathrm{ml}$ of egg suspension was added immediately afterward. Three replicates were conducted for each treatment. Eggs were examined for fertilization envelopes about 15 min after salinity was restored to about 32 psu.

\section{Salinity stress control experiment}

One control experiment was conducted to test the possibility that sudden exposure to low salinity would itself initiate development of a fertilization envelope or cell division. A $0.5-\mathrm{ml}$ volume of egg suspension (approximately 350 eggs) was added to each of three dishes containing 40 $\mathrm{ml}$ of seawater at either 18 or $20 \mathrm{psu}$. Three additional dishes of egg suspension at 32 psu served as controls. The eggs were examined at $100 \times$ after 1 and after $3.5 \mathrm{~h}$ for the presence of fertilization envelopes and multi-cellularity.

\section{Statistical analysis}

Where appropriate, one-way ANOVA was used to compare mean differences across treatments. Percentage data were arcsin transformed before analysis. When there was zero variance within a treatment (i.e., $0 \%$ fertilization across all replicates) those data were excluded from the analysis to meet assumptions of the ANOVA. When significant treatment effects were found, post hoc tests were conducted for all pairwise comparisons using Student's t tests with Bonferroni's correction. All tests were conducted using SPSS ver. 17.0. 


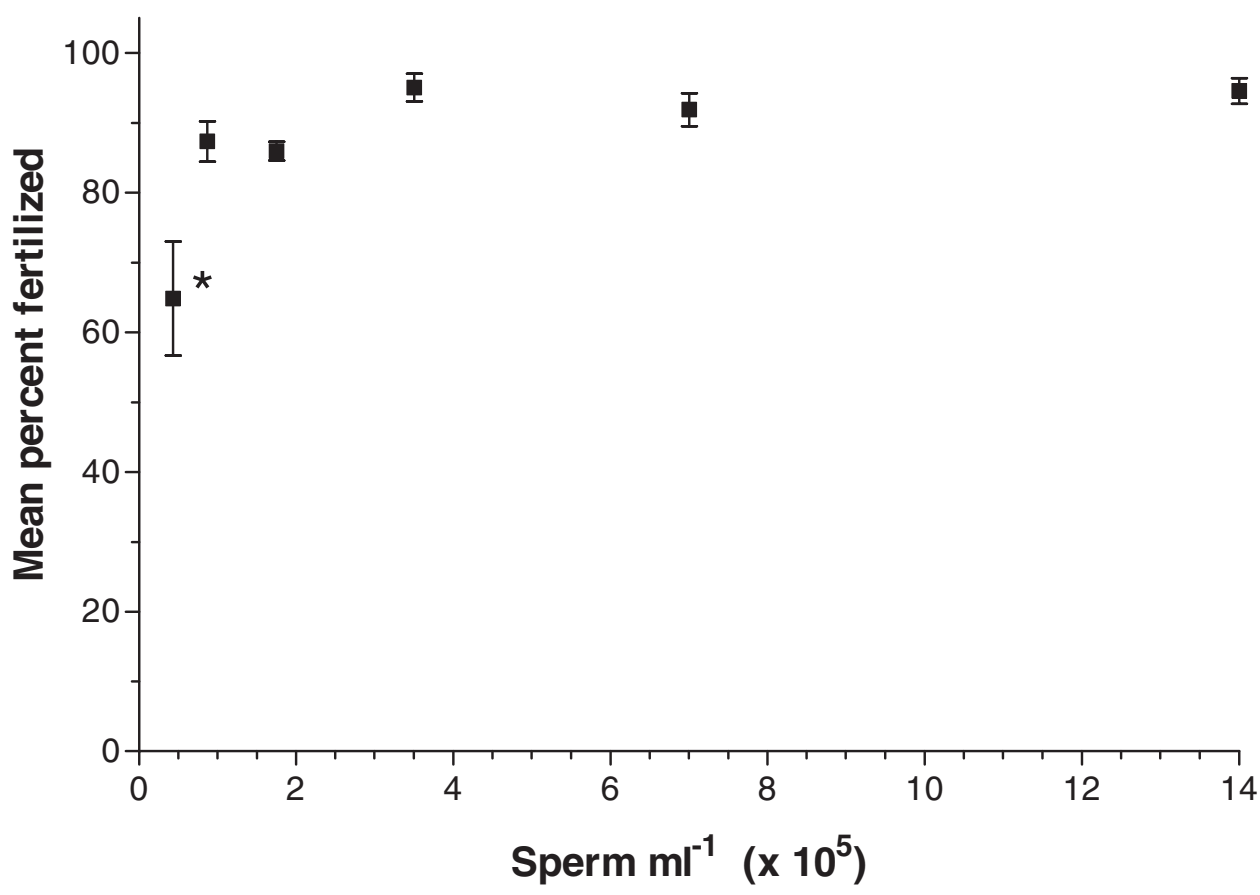

Figure 1. The influence of sperm concentration on average fertilization success in Echinarachnius parma Between 15 and 30 eggs were generally subsampled per replicate. Error bars indicate one SD about the mean. The * indicates the one mean that is significantly different from the others (post hoc test, $P<0.05$ ).

\section{Results}

Sea surface (2-m depth) salinity at the lower Harpswell buoy ranged between 22 and 30 psu during the summer of 2008, and between 15 and 30 psu in the summer of 2009. In August 2009, direct measurements of salinity over the sand dollar bed ranged between 21 and 32 psu.

No eggs showed fertilization envelopes or cleavage without the deliberate addition of sperm, demonstrating that eggs were not inadvertently contaminated with sperm during collection and handling and that exposure to low salinity did not in itself initiate development. Moreover, fewer than $5 \%$ of eggs were ever fertilized when added to the final rinse water after transfer of eggs between salinities, showing that the washing techniques were effective in removing most sperm.

At normal salinities of $32 \mathrm{psu}$, sand dollar eggs formed conspicuous fertilization envelopes over a wide range of sperm concentrations, from about $4.2 \times 10^{4} \mathrm{sperm} \mathrm{ml}^{-1}$ to the highest concentration tested, $1.4 \times 10^{6} \mathrm{sperm} \mathrm{m}^{-1}$ (Fig. 1). More than $60 \%$ of eggs were fertilized at the lowest concentration tested (about $4.2 \times 10^{4}$ sperm ml${ }^{-1}$ ). As expected, there was a significant effect of sperm concentration on fertilization success (ANOVA; $F_{5,12}=7.5 ; P=$ 0.002 ), with the lowest sperm concentration resulting in significantly lower fertilization compared with that obtained at all higher sperm concentrations (post hoc test, $P<0.05$ ). All further studies were conducted using sperm concentrations of about $1 \times 10^{6}$ sperm $\mathrm{ml}^{-1}$.
In a preliminary study, salinity had a significant effect on fertilization success (ANOVA; $F_{4,10}=1421.4 ; P<0.001$ ) and cleavage success (ANOVA; $F_{3,8}=124.6 ; P<0.001$ ). Fertilization and cleavage rates were significantly higher at salinities of $25 \mathrm{psu}$ and above than they were at 20 psu and below (post hoc test, $P<0.05$; Fig. 2). At 10 psu, the lowest salinity tested, no eggs cleaved or formed fertilization envelopes. In more detailed studies conducted subsequently (Fig. 2), reduced salinity again affected the success of both fertilization (ANOVA; $F_{4,10}=105.3 ; P<0.001$ ) and cleavage (ANOVA; $F_{5,12}=97.2 ; P<0.001$ ). Both fertilization and cleavage were significantly greater at salinities of $26 \mathrm{psu}$ and above than at salinities of 24 psu and below (post hoc test, $P<0.05$ ). In particular, fewer than $20 \%$ of eggs showed fertilization envelopes or cleavage at salinities of 22 psu or less. Fertilization envelopes rarely formed (generally $<10 \%$ of the time) at salinities between 15 and 18 psu.

When gametes were mixed at normal (32 psu) salinity, $>90 \%$ of the eggs consistently became fertilized (Fig. 3a); of those eggs that became fertilized, $>80 \%$ underwent at least one cleavage within $1.5 \mathrm{~h}$ of fertilization and nearly $100 \%$ exhibited at least one cleavage over the next $1.5 \mathrm{~h}$ (Fig. 3b). Many eggs took longer to produce fertilization envelopes (Fig. 3a) and to cleave (Fig. 3b) at intermediate salinities (20-26 psu and 22-26 psu, respectively). Even 8-10 h after insemination, reduced salinity significantly lowered percent fertilization $\left(\right.$ ANOVA; $F_{6,14}=190.1$; 

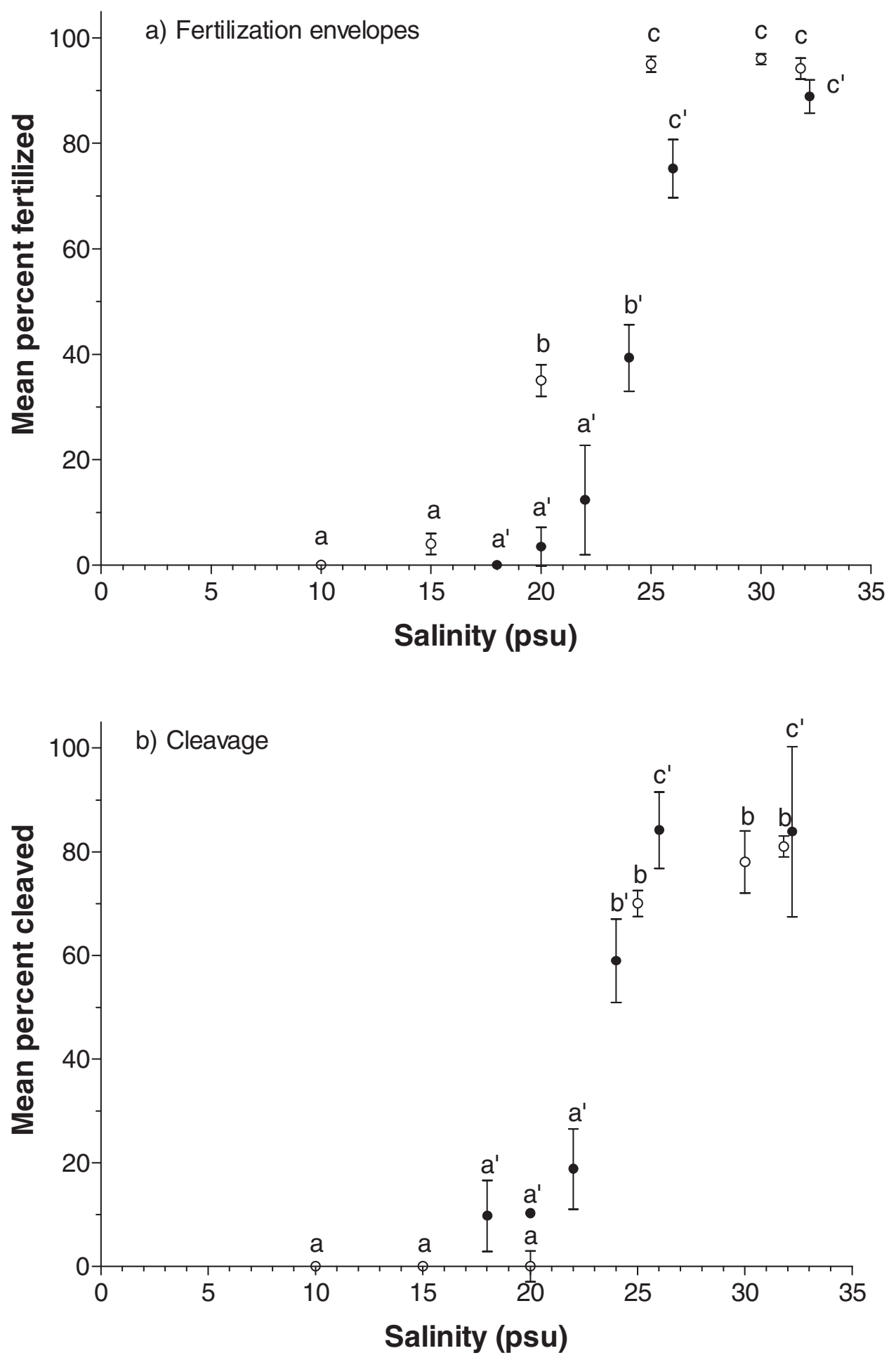

Figure 2. Influence of salinity on production of fertilization envelopes (a) and cleavage (b) in Echinarachnius parma. Results from 2 separate experiments are shown, with 3 replicates per treatment. In one experiment (open symbols), 44-115 eggs were examined per replicate. In the other experiment (closed symbols), 30-75 eggs were examined per replicate. Fertilization was assessed after 5-10 min; cleavage was assessed about $2 \mathrm{~h}$ later. Error bars indicate one SD about the mean. Different letters above each data point indicate significant differences between means, with prime signs indicating the comparisons associated with the second experiment (post hoc test, $P<0.05$ ). Data for the 32 psu control salinity are displaced slightly for both experiments to improve presentation clarity. 

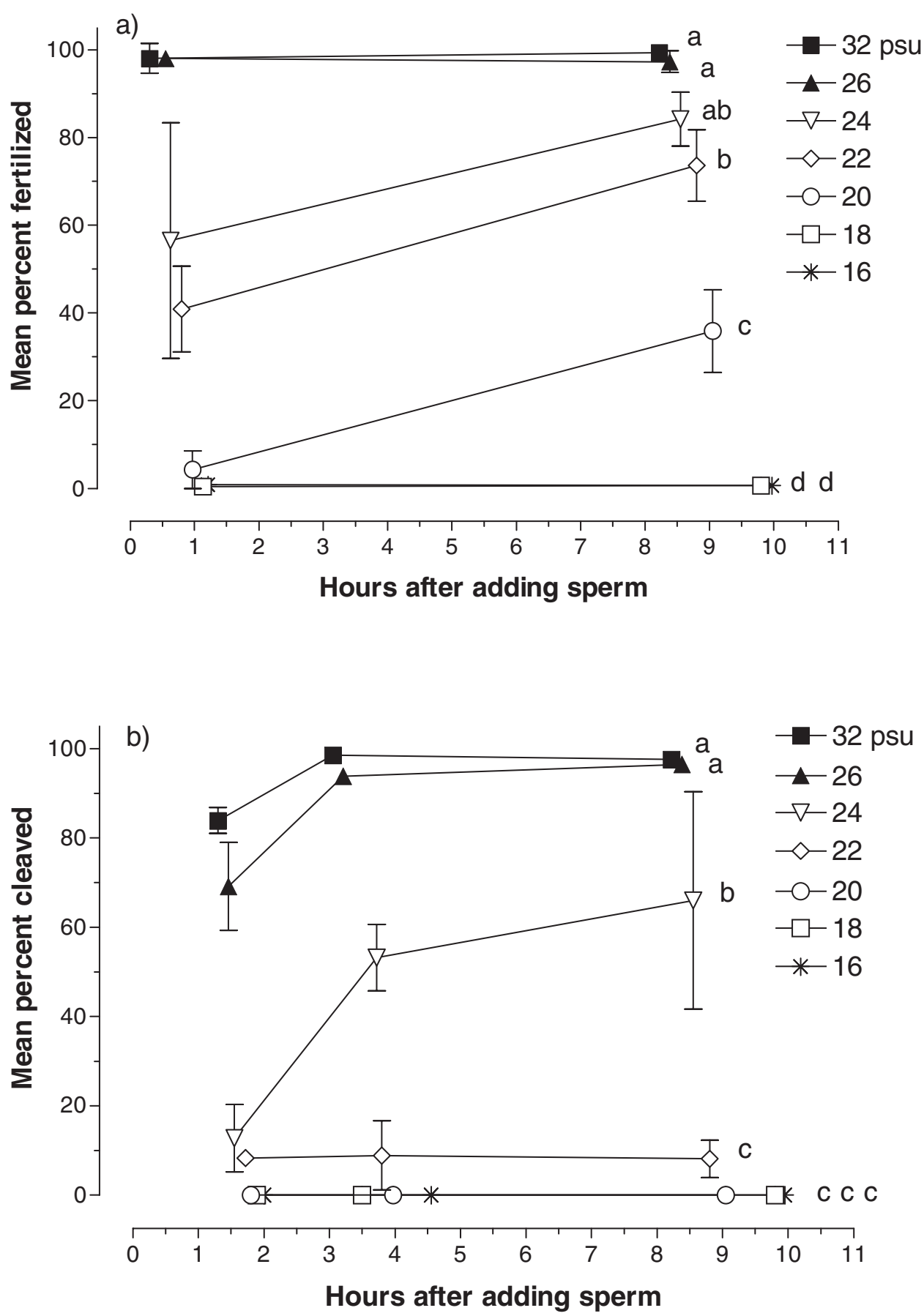

Figure 3. Influence of salinity on the timing of production of fertilization envelopes (a) and cleavage (b) in Echinarachnius parma. Each point is the mean of 3 replicates, with 42-116 eggs examined per replicate for (a) and 25-100 eggs examined per replicate for (b). Error bars indicate one SD about the mean. Letters to the right of each line indicate significant differences between means at the last time point measured (post hoc test, $P<0.05)$.

$P<0.001$ ) for eggs held at 24 psu and below (post hoc test, $P<0.05$ ). In addition, the percentage of eggs that had cleaved $8-10 \mathrm{~h}$ post-insemination was significantly lowered (ANOVA; $F_{3,8}=129.4 ; P<0.001$ ) for eggs held at $24 \mathrm{psu}$ and below (post hoc test, $P<0.05$ ). We recorded no fertilization envelopes or cleavage at the lowest salinities tested (18 and $16 \mathrm{psu}$ ) even $9-10 \mathrm{~h}$ after sperm were added. The percent of embryos cleaving significantly increased between the initial and final readings for salinities between 24 and 32 psu (t test, df $=4, P<0.05$ ); however, the 


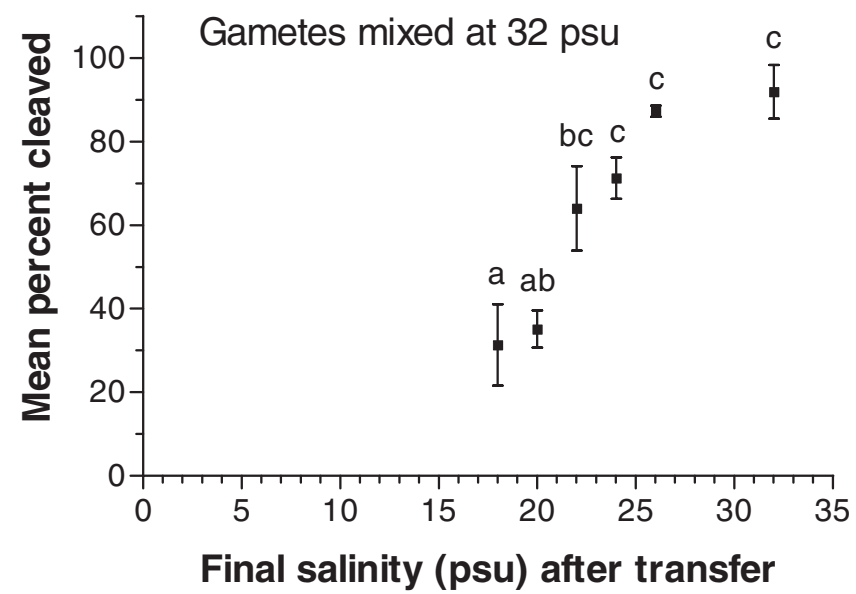

Figure 4. The influence of low salinity on cleavage. Eggs and sperm of Echinarachnius parma were mixed at 32 psu and then transferred to the salinities indicated. Cleavage was assessed about 90 min later. Each point is the mean $( \pm 1 \mathrm{SD})$ of 3 replicates, with $30-57$ eggs examined per replicate. Letters above each data point indicate significant differences between means (post hoc test, $P<0.05$ ).

percent cleaving did not significantly increase between the 3-h time reading and the final reading for any of the salinities (t test, $\mathrm{df}=4, P>0.11$ ). For example, at 24 psu the percentage of eggs seen cleaving increased substantially between 1.5 and $3 \mathrm{~h}$ after gametes were mixed together $(\mathrm{t}=$ 6.607 , df $=4, P=0.0027$ ), but did not significantly increase further over the next $5 \mathrm{~h}$ (Fig. $3 \mathrm{~b}$ ).

When eggs were fertilized at high salinity and later transferred to low salinity, a surprisingly high percentage of eggs (about $30 \%-35 \%$ on average) cleaved at the lowest salinities tested, 18 and 20 psu (Fig. 4). However, post-transfer salinity still had a significant depressive effect on cleavage success (ANOVA; $F_{5,11}=13.997 ; P<0.001$ ). Similarly, transferring eggs from salinities of 18 and 20 psu to fullstrength seawater ( $32 \mathrm{psu}$ ) after they had been mixed with sperm for $15 \mathrm{~min}$ at low salinity rescued many of the eggs (Fig. 5). For example, whereas fewer than $2 \%$ of eggs cleaved when the gametes were left at $18 \mathrm{psu}$, more than $20 \%$ of eggs, on average, cleaved after being transferred from $18 \mathrm{psu}$ to $32 \mathrm{psu}$. Again, this effect of post-fertilization salinity transfer was significant (ANOVA; $F_{5,14}=212.1$; $P<0.001$ ). Very few of the eggs (only $2.26 \% \pm 0.95 \%$ ) added to the rinse water for this treatment became fertilized.

Sperm were remarkably tolerant of low salinity. They retained nearly their full capacity to fertilize eggs even after spending $30 \mathrm{~min}$ at $18 \mathrm{psu}$, a salinity that supported little cleavage (Figs. 2b, 3b). In our intial sperm-tolerance experiment, sperm were observed to swim and bind to eggs at 18 and $20 \mathrm{psu}$ even after $30 \mathrm{~min}$ of exposure prior to egg introduction. However, the low salinities of this initial experiment prevented us from assaying fertilization or cleavage. In our second sperm-tolerance experiment, sperm activity was assayed at 32 psu. Exposures of sperm to 18 psu for $5,10,15$, and 30 min resulted in high levels of fertilization (mean \pm S.D.; $94.9 \% \pm 0.22 \%$; $94.6 \% \pm 1.43 \%$; $94.51 \% \pm 2.69 \%$; and $91.5 \% \pm 0.71 \%$, respectively). There were no significant effects of the low-salinity incubation on the ability of sperm to subsequently fertilize eggs at full salinity (ANOVA; $F_{3,8}=3.047 ; P=0.092$ ).

\section{Discussion}

The lower limit for successful fertilization and cleavage in Echinarachnius parma was about 24 psu. Fertilization occurred, but was delayed, at salinities of 20 and $22 \mathrm{psu}$; however, subsequent cleavage occurred in less than $10 \%$ of fertilized embryos. At salinities less than 20 psu, no eggs produced fertilization envelopes or cleaved, even by $10 \mathrm{~h}$ after insemination. Although few studies have explicitly examined the link between salinity and the ability to produce fertilization envelopes, a reduction in fertilization success between 18 and 24 psu does not appear to be unusual for echinoderms. For example, in the asteroid Asterina pectinifera, fertilization envelopes do not form at salinities below 18 psu (Kashenko, 2006). Similarly, in the holothuroid Eupentacta fraudatrix, 20 psu marked the lower salinity limit for successful fertilization (Kashenko, 2000). For the echinoid Echinocardium cordatum, the lowest salinity at which fertilization envelopes were produced was 24 psu (Kashenko, 2007). In the sand dollar Scapechinus mirabilis, fertilization envelopes were produced down to salinities of 22 psu, but embryos maintained at these low salinities did not survive to the blastula stage (Bekova et al., 2004).

Although echinoderms are typically regarded as stenohaline, restricted to areas of undiluted seawater, some species do occur in estuarine habitats. The gametes of some of these estuarine species can acclimate to the altered salinity at which the adult resides during gametogenesis (Hintz and Lawrence, 1994). However, the more typical response may be a lack of acclimation to reduced salinities, as has been shown for several echinoid species (Roller and Stickle, 1993, 1994). In our study we did not allow adults or gametes to acclimate to changes in salinity. Future studies may benefit from allowing adults to acclimate to such changes prior to spawning or from inducing animals to release gametes directly into containers at the experimental salinity. The general inability of echinoderm gametes to acclimate or adapt to low salinities may partly explain why members of this phylum have yet to invade freshwater habitats. Adult echinoderms also occur in hypersaline environments up to 46 psu (Binyon, 1966), and we suggest that future work on the effects of elevated salinities on fertilization success is warranted.

Echinoderms are not alone among marine organisms in displaying reduced developmental success at low salinities. In the polychaetes Nereis virens and Hydroides elegans, normal fertilization and development do not usually occur 


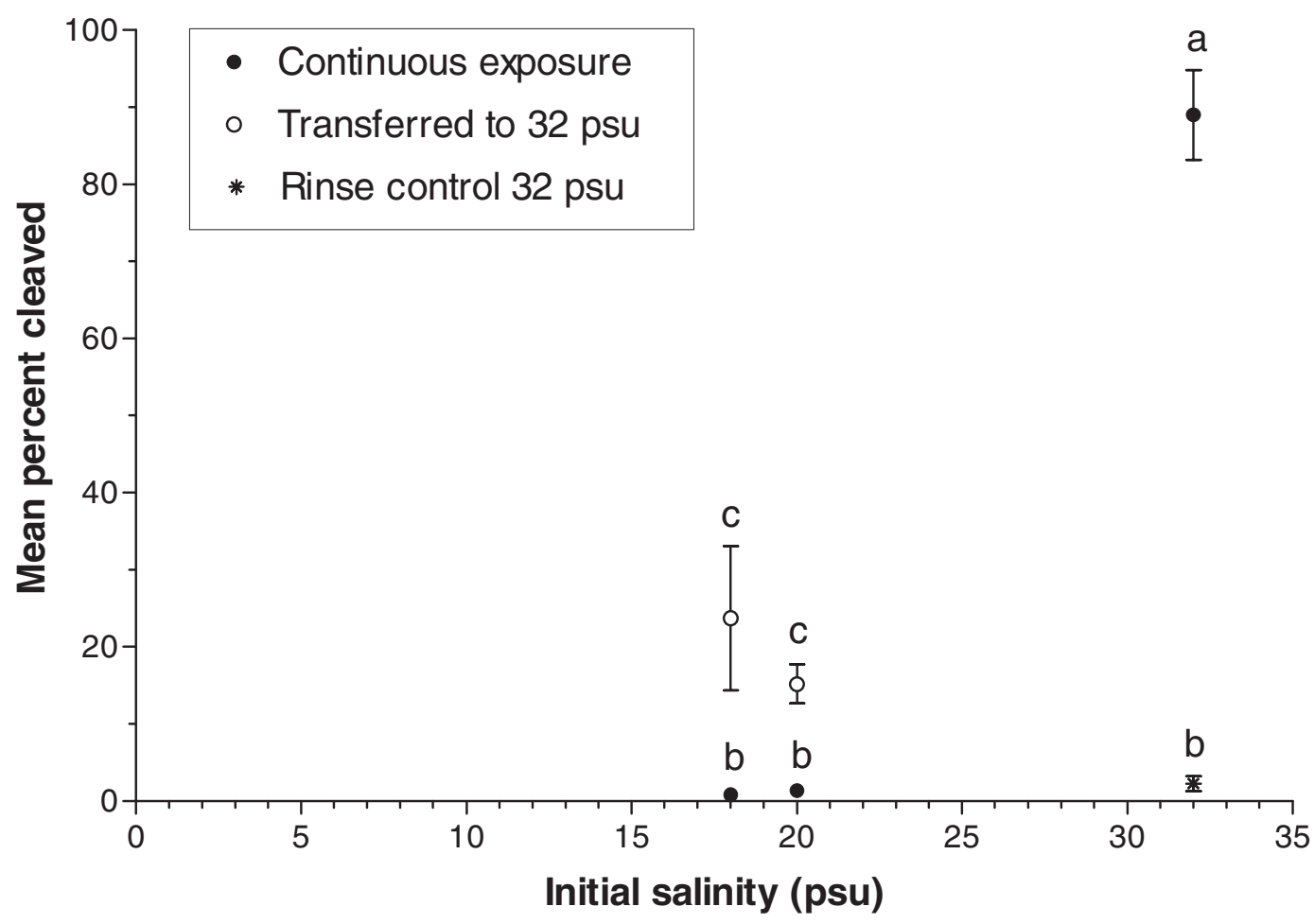

Figure 5. Assessing the ability of fertilized eggs to recover when transferred to normal salinity after having been fertilized at low salinity. Gametes of Echinarachnius parma were mixed at the salinities indicated and either transferred back to seawater of the original low salinity (controls) or to full-strength seawater ( $32 \mathrm{psu}$ ). In the rinse, control unfertilized eggs were placed in water used to rinse excess sperm from eggs prior to transfer to full-strength seawater. Percent cleavage was assessed about $2 \mathrm{~h}$ later. Each point is the mean $( \pm 1 \mathrm{SD})$ of 3 replicates, with about 30-100 eggs examined per replicate. Letters above each data point indicate significant differences between means (post hoc test, $P<0.05$ ).

below salinities of 18 psu and 20 psu respectively (Ushakova and Sarantchova, 2004; Pechenik et al., 2007). Developmental success was also reduced when gametes of marine fishes (e.g., the California grunion-Matsumoto and Martin, 2008) and estuarine fishes (e.g., Fundulus heteroclitusAble and Parmer, 1988) were exposed to low-salinity seawater.

While previous studies have shown that the eggs and embryos of E. parma (Just, 1922a, b) and some other invertebrates are sensitive to changes in salinity, the reason for this sensitivity has remained unclear. One explanation is that a failure of development reflects a failure of fertilization, due to effects on sperm motility or binding ability. In contrast, development may fail after the eggs have been fertilized but before cleavage can occur. In one of the few studies to attempt to tease out the causes of failed development at low salinities for marine animals, Pechenik et al. (2007) found that at least the early stages of fertilization in the polychaete Hydroides elegans could be successful at low salinities; as in the present study with E. parma, development was substantially rescued when well-rinsed eggs were transferred from a sperm-egg mixture at low salinity to a substantially higher salinity. Pechenik et al. (2007) did suggest, however, that sperm function was also reduced at lower salinities, so that both gametes played a role in poor development under low-salinity conditions.

In our study, the sperm of E. parma were very resilient to low-salinity stress and were able to fertilize eggs even after spending $30 \mathrm{~min}$ at 18 psu before being exposed to eggs at normal salinity. We also found that eggs could be rescued by transferring zygotes from low salinity to high salinity, indicating that at least the early steps of fertilization had occurred in some eggs at the lower salinity, and that many eggs fertilized at normal salinity were unable to cleave after being transferred to water of reduced salinity. These results suggest that, in E. parma, developmental failure occurs either at the later steps of fertilization (e.g., pronuclear fusion and egg activation) or at the zygote stage (mitosis) rather than at the level of individual gametes. The rescue effect could be due to sperm that remained bound to the egg surface and that then fertilized the egg upon the egg's return to full-strength seawater. However, this seems unlikely given that only $2.26 \%$ of eggs were fertilized in the rinse control, but $15.23 \%$ (20 psu) and $23.67 \%$ (18 psu) were fertilized in our two rescue treatments. These differences between the control and the rescue treatments mean that 
between $12.98 \%$ and $21.41 \%$ of the eggs were rescued at 20 and 18 psu respectively.

The facts that many fertilized eggs did not cleave after being transferred to low-salinity seawater and that eggs could be rescued by transferring them from a sperm suspension at low salinity to full-strength seawater in the absence of sperm suggest that cleavage (e.g., mitosis) is directly impacted by reduced salinity. Further studies will be needed to determine how this effect is mediated. Reduced osmotic pressure might affect microtubule-stabilizing proteins (Sharp, 2002) or the operation of the protein motors involved in separating the spindles during mitosis (Sharp et al., 2000a, b; Rogers et al., 2004), or might affect cytokinesis directly (Gilbert, 2003). In an ecological context, the ability of eggs to be fertilized at low salinity may be of value in nearshore environments with short-term oscillations in salinity. If natural populations of sand dollar eggs are fertilized at low salinity and subsequently return to undiluted seawater (or possibly just less dilute seawater) through mixing of the water column, then it appears likely that subsequent development can proceed normally. Future studies should investigate whether this rescue effect is present in other marine organisms.

A handful of other studies have also examined the relative abilities of sperm and eggs to tolerate salinity stress. Greenwood and Bennett (1981) exposed eggs and sperm of the sea urchin Parechinus angulosus to low salinities prior to fertilization and found that subsequent fertilization success at 34 psu was strongly affected by prior low-salinity exposure, dropping below 50\% fertilization at about 20 psu. Greenwood and Bennett (1981) also found that sperm were more resilient than eggs to lowered salinities, retaining the ability to fertilize eggs down to $3 \mathrm{psu}$, whereas eggs lysed at salinities below 15 psu. Similarly, in marine fish, sperm were able to retain their motility and tolerate salinities as low as 10 psu (Billard, 1978).

Sperm may be robust to changes in salinity, but they are not immune to its effects. In an estuarine polychaete, for example, sperm retained functionality down to $20 \mathrm{psu}$, but at $10 \mathrm{psu}$ and below the acrosome was destroyed and organelles were lost (Hsieh, 1997). In other species, sperm may indeed be the gamete that limits fertilization success at reduced salinity. In herring, sperm motility was reduced at low salinities, and this reduced motility was implicated as a main factor in poor fertilization success (Griffin et al., 1998). Similarly, in the fifteen-spined stickleback, the longevity of sperm was significantly reduced at salinities below 10 psu (Elofsson et al., 2003).

Additionally, exposure of eggs to low salinities may contribute to increased polyspermy because the "fast block" to polyspermy is sodium-dependent in many marine invertebrates (Jaffe, 1980). Since sodium is also required for proper formation of the fertilization envelope (the "slow block" to polyspermy) and for embryogenesis in echinoids
(Schuel et al., 1982), some of the failure to cleave may be directly attributable to low concentrations of sodium ions. In marine algae, reduced salinity has been shown to increase polyspermy (Brawley, 1992) and to delay fertilization and cleavage (Serrao et al., 1999). This is similar to our result that at intermediate salinities (20-26 psu) the appearance of fertilization envelopes and early cleavage were delayed; the mechanism for this delay should be explored in future studies. To properly address the interactions between salinity, polyspermy, and fertilization success in this and other species, future studies should be carried out over a wide range of sperm concentrations, as has been suggested by Marshall (2006).

Our finding that fertilization envelopes do not always rise at low salinities (e.g., $18 \mathrm{psu}$ ), even in successfully fertilized eggs, was unanticipated. In one experiment, fewer than $2 \%$ of eggs, on average, evidenced fertilization envelopes, and yet about $25 \%$ of those eggs cleaved after their transfer to full-strength seawater (32 psu). Clearly, at least the early events of fertilization (e.g., sperm-egg binding) were successful at low salinity. So, while it is common to judge fertilization success by the elevation of a fertilization envelope (e.g., Greenwood and Bennett, 1981; Ringwood, 1992; Levitan, 2002), this method may underestimate fertilization success at low salinity, and perhaps also under some other stressful conditions such as extreme polyspermy (Levitan, 2002). Further studies will be needed to determine why some fertilized eggs failed to form fertilization envelopes at low salinities. For example, binding of sperm with the egg envelope may have failed to release internal calcium stores (Swann and Jones, 2002; Gilbert, 2003), or cortical granules may have failed to bind to the egg envelope or to release their contents (Swann and Jones, 2002; Gilbert, 2003), or the osmotic gradient across the envelope at reduced salinity may simply have been insufficient to allow for sufficient inward diffusion of water (Gilbert, 2003).

Finally, decreased salinities in the marine realm are often coupled with increases in temperature. For example, in recent decades sea surface temperatures in the Gulf of Maine have been increasing at the same time that salinities have been decreasing (Drinkwater et al., 2009). It is possible that in nature the gametes of marine invertebrates experience salinity and temperature stresses that act synergistically or antagonistically on development, as has been shown to occur for zooplankton experiencing multiple stressors (Folt et al., 1999).

\section{Acknowledgments}

Thanks to Olivia Ambrogio for suggesting one of the sperm tolerance protocols and to Rachel Dicker and Ashton Bunce for help scoring fertilization in the lab. Thanks also to Margaret Pizer for helpful comments on a draft of this manuscript. 


\section{Literature Cited}

Able, K. W., and R. E. Parmer. 1988. Salinity effects on fertilization success and larval mortality of Fundulus heteroclitus. Copeia 2: 345350 .

Anger, K., E. Spivak, and T. Luppi. 1998. Effects of reduced salinities on development and bioenergetics of early larval shore crab, Carcinus maenas. J. Exp. Mar. Biol. Ecol. 220: 287-304.

Bekova, N. V., E. V. Zhuravel, and N. K. Khristoforova. 2004. Effects of desalination and the detergent sodium dodecylsulphate on the early development of the sand dollar Scaphechinus mirabilis. Russ. J. Mar. Biol. 30: 175-182.

Billard, R. 1978. Changes in structure and fertilizing ability of marine and freshwater fish spermatozoa diluted in media of various salinities. Aquaculture 14: 187-198.

Binyon, J. 1966. Salinity tolerance and ionic regulation. Pp. 359-377 in Physiology of Echinodermata, R. A. Boolotian, ed. Interscience, New York.

Brawley, S. H. 1992. Fertilization in natural populations of the dioecious brown alga Fucus ceranoides and the importance of the polyspermy block. Mar. Biol. 113: 145-157.

Byrnes, W. M., and W. R. Eckberg. 2006. Ernest Everett Just (18831941). An early ecological developmental biologist. Dev. Biol. 296: $1-11$.

Drinkwater, K. E., F. Mueter, K. D. Friedlan, M. Taylor, G. L. Hunt, J. Hare, and W. Melle. 2009. Recent climate forcing and physical oceanographic changes in Northern Hemisphere regions: a review and comparison of four marine ecosystems. Prog. Oceanogr. 81: 10-28.

Elofsson, H., K. Van Look, B. Borg, and I. Mayer. 2003. Influence of salinity and ovarian fluid on sperm motility in the fifteen-spined stickleback. J. Fish Biol. 63: 1429-1438.

Folt, C. L., C. Y. Chen, M. V. Moore, and J. Burnaford. 1999. The effects of multiple stressors on freshwater and marine ecosystems. Limnol. Oceanogr. 44: 864-877.

Gilbert, S. 2003. Developmental Biology, 7th ed. Sinauer Associates, Sunderland, MA.

Greenwood, P. J., and T. Bennett. 1981. Some effects of temperaturesalinity combinations on the early development of the sea urchin Parechinus angulosus (Leske) fertilization. J. Exp. Mar. Biol. Ecol. 51: 119-131.

Griffin, F. J., M. C. Pillai, C. A. Vines, J. Kaaria, T. Hibbard-Robbins, R. Yanagimachi, and G. N. Cherr. 1998. Effects of salinity on sperm motility, fertilization, and development in the Pacific herring, Clupea pallasi. Biol. Bull. 194: 25-35.

Hintz, J. L., and J. M. Lawrence. 1994. Acclimation of gametes to reduced salinity prior to spawning in Luidia clathrata (Echinodermata: Asteroidea). Mar. Biol. 120: 443-446.

Hsieh, H. L. 1997. Self-fertilization: a potential fertilization mode in an estuarine polychaete. Mar. Ecol. Prog. Ser. 147: 143-148.

Jaffe, L. A. 1980. Electrical polyspermy block in sea urchins: nicotine and low sodium experiments. Dev. Growth Differ. 22: 503-507.

Johnson, S. L., and P. O. Yund. 2008. Multiple paternity and subsequent fusion-rejection interactions in a kin-structured population. Mar. Ecol. Prog. Ser. 364: 129-134.

Just, E. E. 1922a. Studies of cell division. I. The effect of dliute sea-water on the fertilized egg of Echinarachnius parma during the cleavage cycle. Am. J. Physiol. 61: 505-515.

Just, E. E. 1922b. The fertilization-reaction in Echinarachnius parma. $\mathrm{V}$. The existence in the inseminated egg of a period of special susceptibility to hypotonic sea-water. Am. J. Physiol. 61: 516-527.

Just, E. E. 1923. The fertilization-reaction in Echinarachnius parma. VIII. Fertilization in dilute sea-water. Biol. Bull. 44: 17-21.

Kashenko, S. D. 2000. Combined effect of temperature and salinity on the development of the holothurian Eupentacta fraudatrix. Russ. J. Mar. Biol. 26: 188-193.
Kashenko, S. D. 2006. The combined effect of temperature and salinity on development of the sea star Asterina pectinifera. Russ. J. Mar. Biol. 32: $37-44$

Kashenko, S. D. 2007. Adaptive responses of embryos and larvae of the heart-shaped sea urchin Echinocardium cordatum to temperature and salinity changes. Russ. J. Mar. Biol. 33: 381-390.

Levitan, D. R. 2002. Density-dependent selection on gamete traits in three congeneric sea urchins. Ecology 83: 464-479.

Levitan, D. R., and C. M. Young. 1995. Reproductive success in large populations: empirical measures and theoretical predictions of fertilization in the sea biscuit Clypeaster rosaceus. J. Exp. Mar. Biol. Ecol. 190: $221-241$

Marshall, D. J. 2006. Reliably estimating the effect of toxicants on fertilization success in marine broadcast spawners. Mar. Pollut. Bull. 52: $734-738$.

Matsumoto, J. K., and K. L. M. Martin. 2008. Lethal and sublethal effects of altered sand salinity on embryos of beach-spawning California Grunion. Copeia 2: 484-491.

Metaxas, A. 1998. The effect of salinity on larval survival and development in the sea urchin Echinomentra lucunter. Invertebr. Reprod. Dev. 34: 323-330.

Pearse, J. S., and R. A. Cameron. 1991. Echinodermata: Echinoidea. Pp. 513-662 in Reproduction of Marine Invertebrates, Vol. 6, A. C. Giese, J. S. Pearse, and V. B. Pearse, eds. Boxwood Press, Pacific Grove, CA.

Pechenik, J. A., J. S. Pearse, and P.-Y. Qian. 2007. Effects of salinity on spawning and early development of the tube-building polychaete Hydroides elegans in Hong Kong: not just the sperm's fault? Biol. Bull. 212: $151-160$.

Pennington, J. T. 1985. The ecology of fertilization of echinoid eggs: the consequences of sperm dilution, adult aggregation, and synchronous spawning. Biol. Bull. 169: 417-430.

Podolsky, R. D. 2002. Fertilization ecology of egg coats: physical versus chemical contributions to fertilization success of free-spawned eggs. J. Exp. Biol. 205: 1657-1668.

Podolsky, R. D., and R. R. Strathmann. 1996. Evolution of egg size in free-spawners: consequences of the fertilization-fecundity trade-off. Am. Nat. 148: $160-173$.

Qiu, J. W., R. Tremblay, and E. Bourget. 2002. Ontogenetic changes in hyposaline tolerance in the mussels Mytilus edulis and M. trossulus: implications for distribution. Mar. Ecol. Prog. Ser. 228: 143-152.

Ringwood, A. H. 1992. Comparative sensitivity of gametes and early developmental stages of a sea urchin species (Echinometra mathaei) and a bivalve species (Isognomon californicum) during metal exposures. Arch. Environ. Contam. Toxicol. 22: 288-295.

Rogers, G. C., S. L. Rogers, T. A. Schwimmer, S. C. Ems-McClung, C. E. Walczak, R. D. Vale, J. M. Scholey, and D. J. Sharp. 2004 Two mitotic kinesins cooperate to drive sister chromatid separation during anaphase. Nature 427: 364-370.

Roller, R. A., and W. B. Stickle. 1993. Effects of temperature and salinity acclimation of adults on larval survival, physiology, and early development of Lytechinus variegatus. Mar. Biol. 116: 583-591.

Roller, R. A., and W. B. Stickle. 1994. Effects of adult salinity acclimation on larval survival and early development of Strongylocentrotus droebachiensis and Strongylocentrotus pallidus (Echinodermata: Echinoidea). Can. J. Zool. 72: 1931-1939.

Schuel, H., R. Schuel, P. Dandekar, J. Boldt, and R. G. Summers. 1982. Sodium requirements in hardening of the fertilization envelope and embryonic development in sea urchins. Biol. Bull. 162: 202-213.

Serrao, E. A., L. Kautsky, and S. H. Brawley. 1996. Distributional success of the marine seaweed Fucus vesiculosus L. in the brackish Baltic sea correlates with osmotic capabilities of Baltic gametes. Oecologia 107: 1-12. 
Serrao, E. A., S. H. Brawley, J. Hedman, L. Kautsky, and G. Samuelsson. 1999. Reproductive success of Fucus vesiculosus (Phaeophyceae) in the Baltic sea. J. Phycol. 35: 254-269.

Sharp, D. J. 2002. Cell division: MAST sails through mitosis. Curr. Biol. 12: R585-R587.

Sharp, D. J., H. M. Brown, M. Kwon, G. C. Rogers, G. Holland, and J. M. Scholey. 2000a. Functional coordination of three mitotic motors in Drosophila embryos. Mol. Biol. Cell 11: 241-253.

Sharp, D. J., G. C. Rogers, and J. M. Scholey. 2000b. Microtubule motors in mitosis. Nature 407: 41-47.

Steen, H. 2004. Effects of reduced salinity on reproduction and germling development in Sargassum muticum (Phaeophyceae, Fucales). Eur. J. Phycol. 39: 293-299.

Swann, K., and K. T. Jones. 2002. Membrane events of egg activation. Pp. 319-346 in Fertilization, D. M. Hardy, ed., Academic Press, San Diego.

Ushakova, O. O., and O. L. Sarantchova. 2004. The influence of salinity on fertilization and larval development of Nereis virens (Polychaeta, Nereidae) from the White Sea. J. Exp. Mar. Biol. Ecol. 301: $129-139$.

Yund, P. O. 2000. How severe is sperm limitation in natural populations of marine free-spawners? Trends Ecol. Evol. 15: 10-13. 